\title{
Riesgo soberano e inversión extranjera directa en Colombia, 2003-2018*
}

\author{
Recibido: 27 de agosto de 2019 • Aprobado: 13 de septiembre de 2019 \\ https://doi.org/10.22395/seec.v22n52a6
}

Cristina Isabel Ramos ${ }^{* *}$

\section{RESUMEN}

Este estudio examina el efecto del riesgo soberano sobre los flujos de inversión extranjera directa (IED) en Colombia, durante el período 2003-2018. Son utilizados datos trimestrales sobre el Embig (Emerging Market Bond Index Global) como proxy del riesgo soberano, IED y un grupo de variables de control. Mediante un análisis de regresión con mínimos cuadrados ordinarios (MCO) y el método de momentos generalizados (MMC), se encuentra que el riesgo soberano tiene un fuerte impacto en la entrada de inversión foránea, explicando alrededor del 22 \% de la variación total en la IED. Se ratifica, además, el efecto sustancial del riesgo soberano sobre la IED con una función impulso respuesta. Al controlar por la tasa de apertura y el ICCO, se concluye que la confianza de los agentes privados y el grado de comercio internacional también son determinantes en la atracción de flujos de capital foráneos.

\section{PALABRAS CLAVE}

Inversión extrajera directa; Embig; series de tiempo; riesgo soberano; Colombia.

\section{CLASIFICACIÓN JEL}

F21, F23, G32, C32.

\section{CONTENIDO}

Introducción; 1. Revisión de literatura; 2. La inversión extranjera directa en Colombia; 3. Metodología;

4. Estimación y resultados; 5 . Robustez y consideraciones finales; 6. Conclusiones; Bibliografía.

\footnotetext{
Trabajo presentado en el curso de Macroeconomía Aplicada, Maestría en Ciencias Económicas, Universidad Nacional de Colombia sede Medellín.

* Profesional en Negocios Internacionales, Universidad de Medellín, Medellín, Colombia. Estudiante de la Maestría en Ciencias Económicas, Universidad Nacional de Colombia, Medellín, Colombia. Asistente editorial revista Semestre Económico, Universidad de Medellín, Medellín, Colombia. Correo electrónico: cramosb@unal.edu.co; isabelbarroso92@gmail.com
} 


\title{
SOVEREIGN RISK AND FOREIGN DIRECT INVESTMENT IN COLOMBIA, 2003-2018
}

\begin{abstract}
This study examines the effect of sovereign risk on the foreign direct investments (FDI) flows in Colombia during the 2003-2018 period. For this purpose, quarterly data about the Embig (Emerging Market Bond Index Global) is used as a proxy for sovereign risk, FDI inward flows and a set of control variables. Through a regression analysis with ordinary least square (OLS) and generalized method of moments (GMM) it is found that sovereign risk has a strong impact on the FDI inward flows, explaining the $22 \%$ of the total FDI variation. It is also ratified the substantial effect of sovereign risk on the FDI inward flows with an impulse-response function. By controlling for a trade openness and a business confidence index, it is concluded that the private agents confidence matter and the trade openness is determining in the attraction of foreign capital inward flows.
\end{abstract}

\section{KEY WORDS}

Foreign direct investment; Embig; time series; sovereign risk; Colombia.

JEL CODE

F21, F23, G32, C32.

\section{CONTENTS}

Introduction; 1. Literature revision; 2. Foreign direct investment in Colombia; 3. Methodology; 4. Estimation and result; 5 . Robustness and concluding remarks; 6 . Conclusions; Bibliography.

\section{RISCO SOBERANO E INVESTIMENTO ESTRANGEIRO DIRETO NA COLÔMBIA, 2003-2018}

\section{RESUMO}

Este estudo analisa o efeito do risco soberano sobre os fluxos de investimento estrangeiro direto (IED) na Colômbia, entre 2003 e 2018. São utilizados dados trimestrais sobre o Emerging Market Bond Index Global (Embig) como proxy do risco soberano, IED e um grupo de variáveis de controle. Por meio de uma análise de regressão com mínimos quadrados ordinários (MQO) método generalizado dos momentos (MGM), encontra-se que o risco soberano tem um forte impacto na entrada de investimento estrangeiro, o que explica ao redor de $22 \%$ da variação total na IED. Além disso, reafirma-se o efeito substancial do risco soberano sobre a IED com uma função impulso-resposta. Ao controlar pela taxa de abertura e pelo ICCO, conclui-se que a confiança dos agentes privados e o grau de comércio internacional também são determinantes na atração de fluxos de capital estrangeiro.

PALAVRAS-CHAVE

Investimento estrangeiro direto; Embig; séries de tempo; risco soberano; Colômbia.

\section{CLASSIFICAÇÃO JEL}

F21, F23, G32, C32.

\section{CONTEÚDO}

Introdução; 1. Revisão de literatura; 2. Investimento estrangeiro direto na Colômbia; 3. Metodologia; 4. Estimativa e resultados; 5 . Robustez e considerações finais; 6 . Conclusões; Bibliografia. 


\section{INTRODUCCIÓN}

El desarrollo de las economías emergentes depende en gran medida de la posibilidad de fomentar grandes inversiones y de la acumulación de capital. El acceso al capital foráneo permite a las economías explotar sectores y oportunidades que de otra manera no sería posible aprovechar, sin embargo, existen factores que pueden frenar y, en ocasiones, rezagar la entrada de flujos de inversión. De acuerdo con Busse y Hefeker (2005), capitales de corto plazo como la inversión de portafolio, tienden a ser muy susceptibles a los cambios en el ambiente económico o a la simple percepción de los inversionistas, por lo que no constituyen una buena fuente para la acumulación de capital y reservas. El capital de largo plazo, como la inversión extranjera directa (IED), por el contrario, provee a las economías acceso a tecnología, financiación, conocimiento, entre otros factores, aunque, al igual que los capitales de corto plazo, depende en gran parte de las condiciones internas que ofrece el país receptor.

Debido al fenómeno globalizador y al desarrollo de las tecnologías de la información y de la comunicación, los flujos de capital han experimentado aumentos significativos, en particular desde la década de 1990, y en algunas regiones como Asia y países emergentes de América Latina, estos aumentos son más significativos al considerarse que existen sectores productivos por explotar, en contraste con las economías desarrolladas.

En un escenario económico caracterizado por diversos intereses políticos, crisis financiera y social, conflictos transnacionales y eventos de diversa índole que pueden afectar los flujos de IED en los países receptores, resulta vital identificar cuáles son los factores que determinan los flujos foráneos de inversión, en particular los factores asociados al riesgo soberano, variable fundamental en la toma de decisiones de inversión.

El análisis de los factores que determinan la IED y en particular el riesgo, sea riesgo político, económico, financiero u otro, ha sido abordado ampliamente en la literatura internacional, sin embargo, en Colombia no existe evidencia empírica sobre el tema, solo algunos estudios que realizan análisis descriptivo o de corte microeconómico. En este sentido, este trabajo se propone estudiar el efecto del riesgo soberano (Embig) sobre la IED en Colombia. Es importante señalar que hablar de riesgo o riesgo país abarca varios tipos de riesgo. De acuerdo con la Guía Internacional de Riesgo de País (ICRG, por sus siglas en inglés), el riesgo se divide en tres categorías: político, económico y financiero, cada uno con distintas mediciones $^{1}$. Para efectos de este estudio, se hará uso del Embig Colombia, construido por JPMorgan Chase y considerado como un tipo de riesgo financiero soberano.

\footnotetext{
Para profundizar sobre las categorías de riesgo, remitirse a PRS Group.
} 
Para alcanzar este objetivo se estima un modelo mediante mínimos cuadrados ordinarios y método de momentos generalizados y se encuentra que el riesgo soberano explica alrededor del $22 \%$ de la variación total en la IED.

Este documento se estructura como sigue: en la primera sección se presenta la revisión de literatura, en la segunda sección se realiza una síntesis de la IED en Colombia, el tercer apartado expone la metodología, el cuarto la estimación y los resultados, en el quinto se muestran la robustez y, en el sexto, las conclusiones.

\section{REVISIÓN DE LITERATURA}

De acuerdo con Kalin (2009) la movilidad de los flujos de capital es un factor sustancial para el crecimiento económico, y es una fuente importante de transferencia de conocimiento y tecnología, sobre todo para las economías emergentes. Una variedad de trabajos se ha concentrado en identificar los principales determinantes que impulsan la IED en los países y cuantificar los efectos. A continuación, se presentarán algunos trabajos que examinan las principales variables que determinan los flujos de inversión directa.

Hunady y Orviska (2014), en un ejercicio aplicado para la Unión Europea, usan un panel de datos para analizar los determinantes de la IED, haciendo especial énfasis en los impuestos corporativos. Entre las variables de control usadas en la regresión se encuentran el PIB per cápita como proxy del tamaño del mercado, grado de apertura económica, una dummy para cuantificar el efecto de la crisis financiera de 2008, y el costo de construcción permitida. Como resultados, se encontró que los impuestos corporativos son estadísticamente no significativos y que las variables de costos laborales, costos de despido, grado de apertura en la economía, PIB per cápita y deuda pública resultaron significativos y con fuerte impacto sobre la IED.

O’Meara (2015), estima un panel de datos con 99 países para el año 2005, e identifica los principales factores que impulsan la IED. La muestra incluye países en desarrollo y países desarrollados, y se encuentra que las variables tradicionales relacionadas con el tamaño y la actividad económica en el país anfitrión son significativas al explicar los flujos de inversión extranjera directa, mientras que variables como la libertad económica, incentivos fiscales (impuestos corporativos) y el stock de capital no afectan la IED.

Algunos trabajos se han concentrado en determinadas variables que impactan los flujos de inversión directa. Tal es el caso de la infraestructura, variable considerada 
en la literatura como un elemento crucial a la hora de tomar decisiones de inversión. En una estimación para Malasia, los investigadores Bakar, Mat y Harun (2012), utilizan como proxy el gasto del gobierno como proporción de PIB real, e incluyen un conjunto de variables de control (PIB per cápita real, grado de apertura comercial y gasto total en educación) para cuantificar los efectos en la IED durante el período 1970-2010 con datos anuales. Como resultado, la estimación reveló un impacto significativo y positivo de la infraestructura sobre la IED. Las variables asociadas al tamaño del mercado, la apertura del mercado y el capital humano también explican gran parte de los flujos de inversión en Malasia.

En América Latina también se han realizado estudios sobre la IED y sus determinantes, se pueden resaltar los trabajos de Correa, Dias y Triches (2017), Amal, Tomio y Raboch (2010) y Gil, López y Espinosa (2013).

Correa, Dias y Triches (2017) analizan los determinantes de la IED en Brasil durante el período 2001-2013. A diferencia de la mayoría de los estudios, estos autores hacen uso de un modelo de corrección de error (VEC, por sus siglas en inglés), y la función de impulso respuesta. Como variables explicativas incluyen el PIB real, la tasa de cambio nominal, la inflación, el grado de apertura, la productividad laboral, los costos laborales, y el precio de las materias primas. Los resultados del estudio muestran que el nivel de la actividad económica (PIB), los salarios y la productividad están positivamente relacionados con las entradas de IED, lo cual significa, de acuerdo con los autores, que los inversores persiguen estrategias de búsqueda de eficiencia cuando se dirigen al mercado brasileño.

Amal, Tomio y Raboch (2010) por su parte, estudian los factores determinantes de la IED en Latinoamérica² entre 1996 y 2008. Para este propósito estiman un panel de datos mediante $\mathrm{MCO}$ conformado por un grupo de regresoras que incluye la tasa de cambio real, la inflación, la tasa de interés, la tasa de crecimiento del PIB y el PIB per cápita, el grado de apertura y un conjunto de variables institucionales (voz y responsabilidad, estabilidad política y ausencia de violencia/terrorismo, efectividad del gobierno, calidad regulatoria, estado de derecho y control de la corrupción), tomadas de los indicadores de gobierno del Banco Mundial. Los resultados empíricos apoyan la hipótesis propuesta por los autores, de que la IED en Latinoamérica está positivamente relacionada con la estabilidad económica, el crecimiento y la apertura del comercio, así como con el avance en el entorno institucional y político, medido por el conjunto de variables institucionales.

Los países incluidos en el análisis son Argentina, Bolivia, Brasil, Colombia, México, Paraguay, Perú y Uruguay. 
En el estudio de Gil, López y Espinosa (2013), se busca identificar las variables que atraen los flujos de inversión directa en los países América del Sur durante 1992-2011. Al estimar un panel de datos mediante GMM, los autores encuentran que la IED rezagada, el PNB per cápita y la tasa de crecimiento del PIB tienen un efecto positivo sobre la IED. Entre las otras variables explicativas incluidas en el modelo se hallan la inflación, la tasa de desempleo y tres variables dummies indicadoras de la existencia de tratados con Estados Unidos, Europa y China.

Finalmente, en el trabajo de Tocar (2018) se realiza un recuento de los principales factores que afectan la IED. Mediante una revisión exhaustiva, el autor define once dimensiones en las cuales, una variedad de factores, pueden influenciar de manera positiva o negativa la IED. En el gráfico 1 se resumen estas dimensiones, así como las variables asociadas a cada dimensión. Como se puede apreciar, el autor define una dimensión asociada con el riesgo país, y otra con factores institucionales que pueden afectar el desempeño de la IED. En la siguiente sección se realizará un recuento de algunos estudios que han integrado en el análisis, el impacto del riesgo país sobre los flujos de inversión, la principal variable objeto de este estudio.

\subsection{Riesgo país e inversión extranjera directa}

Existe un conjunto de factores que pueden influir de manera negativa en las decisiones de inversión en un país, y están asociados con el nivel de riesgo país, una de las principales preocupaciones de los inversores al incursionar en un mercado foráneo.

El riesgo país o nivel de riesgo se ha abordado de manera bastante heterogénea en la literatura, hasta el punto que se cuenta con un rango de variables proxy para su medición. Rafat y Farahani (2019), en su propósito de estudiar el impacto del riesgo político sobre los flujos de inversión directa en Irán durante 1985-2016, estiman un modelo mediante mínimos cuadrados en dos etapas y encuentran que, controlando por el nivel de inflación, PIB a precios corrientes, grado de apertura y tipo de cambio, el riesgo político es altamente significativo e influye de manera negativa sobre los flujos de inversión. La información sobre riesgo político se toma de la Guía Internacional de Riesgo de País (ICRG, por sus siglas en inglés) proporcionada por el Grupo de Servicios de Riesgo Político, quienes especifican un indicador de riesgo político, económico y financiero. El riesgo político a su vez se divide en doce categorías que miden diferentes aspectos de la institucionalidad, conflicto y gobierno ${ }^{3}$. Respecto a estas categorías en particular, los autores encontraron que

${ }^{3}$ Las doce categorías del componente del riesgo político son: estabilidad del gobierno, expropiación, régimen político, conflicto interno, conflicto externo y presiones diplomáticas, corrupción, influencia de los militares en la política, tensiones religiosas, imparcialidad del sistema legal (ley y orden), tensiones entre grupos étnicos, libertades civiles y derechos políticos (democracia), nivel de burocracia. 
el conflicto externo, las tensiones étnicas, la condición socioeconómica, el perfil de la inversión y las tensiones militares y religiosas, son significativos al momento de explicar el comportamiento de los flujos de inversión extranjera en Irán.

En una aplicación para Argelia, Sissani y Belkacem (2014) estudian el impacto del riesgo país y sus tres categorías (riesgo político, económico ${ }^{4}$ y financiero ${ }^{5}$ ) en la IED en el período 1990-2012. El riesgo país y los tres componentes fueron tomados de los indicadores de la ICRG. Finalmente, los resultados dan cuenta de un coeficiente positivo y significativo para los riesgos político y financiero. Se encontró que si el riesgo político aumenta en $1 \%$ la IED incrementa en 0,15 \%, si el riesgo económico aumenta en $1 \%$, la IED decrece en $0,33 \%$ y si el riesgo financiero aumenta en $1 \%$ la IED incrementa en $0,89 \%$.

Türedi (2018) por su parte, evalúa el efecto de la corrupción y el riesgo país sobre la IED en 49 países en desarrollo durante 2002-2015. Mediante la estimación de un panel y la técnica de GMM, integran un conjunto de variables de control (inflación, población, PIB, apertura comercial, capital físico), variables relacionadas con el riesgo país (indicadores de riesgo político, económico y financiero de la ICRG), y los índices de control de corrupción y estado de derecho. El análisis empírico reveló los siguientes hallazgos: i) una disminución en la corrupción y el riesgo país afecta positivamente las entradas de IED; ii) el riesgo financiero, no tiene un efecto significativo en las entradas de IED, mientras que una caída en el nivel de riesgo económico y político acelera las entradas de IED. Con base en estos resultados, el autor concluye que los países en desarrollo pueden atraer más IED creando una estructura institucional de calidad, combatiendo la corrupción y creando políticas macroeconómicas sólidas que mejoren el clima de inversión y reduzcan la incertidumbre y la percepción de riesgo.

\footnotetext{
${ }^{4}$ El riesgo económico está relacionado con aspectos macroeconómicos que pueden afectar las transacciones comerciales y mediante cinco componentes: PIB per cápita, tasa de crecimiento del PIB, inflación, balance presupuestario nacional.

${ }^{5}$ El riesgo financiero se asocia con la posibilidad de impago de las obligaciones externas de un país y se mide a través de cinco componentes: deuda externa como porcentaje del PIB, servicio de la deuda externa, exportaciones de bienes y servicios y estabilidad de la tasa de cambio.
} 


\section{Gráfico 1. Determinantes de la IED}

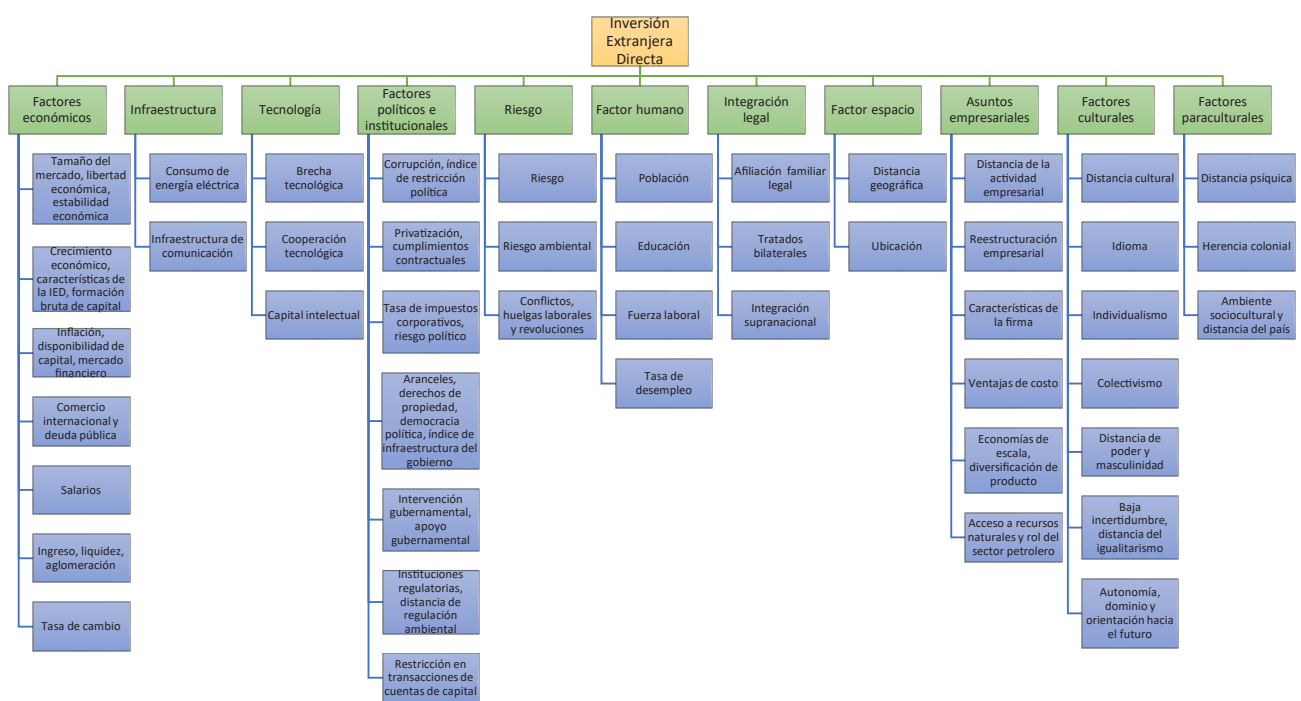

Fuente: elaboración propia con información de Tocar (2018).

Hayakawa, Kimura y Lee (2013) investigan los efectos del riesgo político y financiero ${ }^{6}$ en 89 países en desarrollo durante 1895-2007. Los autores utilizan una muestra de 294 países y realizan estimaciones para toda la muestra y para los países en desarrollo (89 países). La estimación mediante GMM y MCO da cuenta de que un menor riesgo financiero no atrae las entradas de IED, especialmente en los países en desarrollo. Solo en la muestra de países en desarrollo, se encuentra que los conflictos internos, la corrupción, la influencia militar en la política y la calidad de la burocracia están inversamente relacionados con los flujos entrantes de IED.

Ismail (2017), en un ejercicio para las regiones del Medio Oriente y África del Norte (MENA, por sus siglas en inglés) y el Cuerno de África ${ }^{7}$, examina cómo el riesgo país (riesgo económico, financiero y político tomado de la ICRG) afecta las entradas de IED, así como las operaciones y la decisión de entrar a este mercado. Controlando con un grupo de variables tradicionales, los resultados de las estimaciones señalan que los niveles de IED en los países de estas regiones y la decisión de ingresar al mercado, así como las operaciones comerciales, se ven afectados por los riesgos políticos, financieros y económicos. Como conclusión, el autor sugiere que es imperativo el reconocimiento por parte de las empresas, la planificación y gestión

6 Los indicadores de riesgo político y financiero se tomaron de la ICRG.

7 Esta región se ubica en la parte oriental de África y está compuesta por ocho países: Yibuti, Eritrea, Etiopía, Kenia, Somalia, Sudán del Sur, Sudán y Uganda. 
de los riesgos como parte de su estrategia de mercado y operaciones comerciales cotidianas.

Finalmente, en un estudio para Brasil, Mattos, Cassuce y Campos (2007) investigan hasta qué punto la entrada de IED en Brasil respondió a los cambios en los niveles de sus principales determinantes entre 1980 y 2004. Al usar un VEC y utilizar un conjunto de regresoras (grado de apertura comercial, tasa de crecimiento del PIB real, tasa de cambio, riesgo e inflación), encuentran que las variables que afectan en mayor grado la IED en Brasil son el riesgo país, el grado de apertura comercial y la tasa de inflación. Es de resaltar que, a diferencia de trabajos presentados previamente, la medida de riesgo país fue calculada como el total de la deuda externa del país como porcentaje del PIB.

Como se puede observar, existe una amplia literatura relacionada con la IED y sus principales determinantes, no obstante, para el caso de Colombia, son realmente pocos los trabajos que abordan este tema y realizan aplicaciones econométricas. Se ha encontrado evidencia de trabajos como los de Kalin (2009), Garavito et al. (2014), Botero (2011) y Echavarría y Zodrow (2003) para el país; sin embargo, son trabajos orientados al análisis descriptivo que incluyen variables asociadas al tamaño del mercado, calidad de la infraestructura, disponibilidad de mano de obra calificada, restricciones al comercio, o la estructura impositiva y su impacto en los flujos de inversión.

Solo en el estudio de Garavito, Iregui y Ramírez (2012) se abordan los determinantes de la inversión extranjera directa en Colombia, aplicando técnicas econométricas, aunque el trabajo no realiza un análisis macroeconómico, sino a nivel de firma.

Otros trabajos aplicados para América Latina como el de Gil, López y Espinosa (2013) y Amal, Tomio y Raboch (2010) realizan aplicaciones empíricas sobre los determinantes de la IED e incluyen a Colombia; no obstante, las técnicas usadas son paneles de datos. Para concluir, este trabajo pretende aportar a la literatura en la medida que provee estimaciones de series de tiempo, poco usual en los estudios de IED y sus determinantes y evalúa el impacto del riesgo país, variable que no ha sido estudiada en al análisis empírico para Colombia.

\section{LA INVERSIÓN EXTRANJERA DIRECTA EN COLOMBIA}

La IED en Colombia ha tenido fuertes impactos en distintas dimensiones de la economía. Desde inicios de la apertura económica en la década de 1990, la IED se ha consolidado como una fuente importante capital externo, así como un factor determinante en la cuenta de capital y la balanza de pagos, según Garavito et al., 
2012 y Fedesarrollo (2007). Además de ser una importante impulsora del crecimiento económico y aportar a la cuenta de capital, también se han visto efectos en el comercio internacional, la productividad, el desarrollo tecnológico y el desempeño de las firmas.

Su impacto en la balanza de pagos se ha comprobado al constituirse como una herramienta crucial para financiar los desbalances corrientes de la economía y proveer acumulación de reservas internacionales. Si bien este proceso ha contribuido a la revaluación del tipo de cambio en algunos períodos, también ha mejorado la liquidez y el sector externo que actúan como atenuantes ante coyunturas internacionales. En cuanto al comercio internacional, los patrones del comercio han cambiado, orientando la actividad comercial en el exterior hacia bienes industriales y, por otro lado, se ha encontrado que un gran número de empresas multinacionales participantes en diversos sectores, han sido propulsoras de la actividad exportadora del país.

Para Fedesarrollo (2007) y Kalin (2009), el desarrollo tecnológico por su parte se ha visto favorecido por la IED, pues se ha encontrado evidencia de los denominados spillovers en diversos sectores, y de la cooperación gremial de las multinacionales y sus casas matrices, que se han materializado como organismos de asistencia técnica e innovación en las firmas.

En cuanto a la productividad se ha encontrado que la IED ha contribuido a mejorarla en algunos sectores, mientras que en el desempeño de las firmas se ha visto un avance en cuanto a la eficiencia.

En la evolución de la IED en Colombia se pueden encontrar tres fases. La primera de ellas inicia en la década de 1970 y se extiende hasta inicios de la década de 1990. En un contexto de protección de la industria doméstica, en línea con el modelo de sustitución de importaciones de la época, y el régimen de control de cambios que operaba para entonces, la IED sufrió de ciertas restricciones, en particular, solo algunos sectores de la economía podían recibir IED y la libre transferencia de capital y utilidades era igualmente limitada. Como se puede ver en el gráfico 2, durante esta primera etapa la IED era incipiente, con un promedio anual que alcanzaba apenas USD 277 millones.

La segunda etapa inicia con la apertura económica a mediados de 1991 hasta el año 2010, y sentó las bases para estimular la atracción de capital extranjero. En esta etapa, las políticas regulatorias del gobierno en lo relacionadas con la IED se flexibilizaron y dieron lugar a la Ley 9 de 1991 que concebía la IED como un elemento importante en aras de abrir las fronteras comerciales del país y de facilitar la financiación y entradas de capital. Mediante esta ley se establecieron los principios de 
igualdad, universalidad y automaticidad que daban vía libre a la IED en la mayoría de los sectores ${ }^{8}$, autorizaba la libre transferencia de capital y utilidades y establecía el trato nacional para inversionistas extranjeros (Botero, 2011). En esta segunda etapa la IED inicia una fase de crecimiento, alcanzando su pico más alto en el año 1997 con USD 5.562 millones. No obstante, se registraron caídas en los años 1999 y 2003. El valor promedio de los flujos de capital entrantes en esta etapa fue de USD 4.021 millones anuales, lo que significó un aumento promedio de $1.352 \%$ con respecto a la primera etapa.

Durante la tercera etapa, 2010-presente, la IED ha experimentado cifras históricas, alcanzando su máximo en el año 2013 con USD 16.209 millones (ver gráfico 2). En esta etapa es de resaltar el esfuerzo por lograr una mayor simplicidad en el régimen y la legislación y mejorar las condiciones para fortalecer la entrada de capital extranjero. A diferencia de la anterior etapa, el régimen actual de la IED solo tiene restricciones en los sectores de defensa y seguridad, y en el procesamiento, disposición y desecho de basuras tóxicas, peligrosas o radioactivas no producidas en el país. los sectores de telecomunicaciones, transporte marítimo y aéreo, y el sector inmobiliario también fueron abiertos a la inversión extranjera. Finalmente, en esta etapa se muestran grandes avances en la consolidación de una política orientada a la atracción de flujos de capital extranjero, en particular, se puede decir que después de la apertura económica, las políticas implementadas por el gobierno nacional en materia de comercio exterior -como el Plan Vallejo, los CERT y los diferentes acuerdos comerciales y tratados bilaterales de inversión en los que participa el país-, han estimulado el cambio del país hacia uno de orientación exportadora, lo cual, por supuesto, se constituye en un atractivo para las multinacionales e incentiva la entrada de IED en la economía, de acuerdo con Kalin (2009)9.

\footnotetext{
8 Por entonces, se establecieron restricciones a la IED en los sectores de telecomunicaciones, transporte marítimo y aéreo, y en los sectores de defensa y seguridad nacional e inmobiliario, la IED fue totalmente prohibida.

9 El Plan Vallejo, aunque data del año 1959, se consolida como una estrategia para el fomento de las exportaciones una vez iniciada la apertura económica en los años 90, y consiste en permitir el ingreso al país de materias primas, insumos, bienes de capital y repuestos, libres de derechos de aduana, a cambio de una contraprestación relacionada con la realización de exportaciones por el mismo importe. En el caso de los CERT, igualmente buscan estimular la actividad exportadora, otorgando el reintegro total o parcial en los que haya incurrido el exportador, en materia de impuestos indirectos, tasas y contribuciones en relación con el proceso de producción y comercialización del producto.
}

En cuanto a los acuerdos comerciales, Colombia cuenta actualmente con 18 acuerdos vigentes, entre uniones aduaneras, acuerdos de libre comercio, acuerdos comerciales preferenciales y acuerdos de asociación económica. En lo que atañe a los tratados bilaterales de inversión, son seis, e incluyen países como Suiza, Reino Unido, China, Perú, España, entre otros, de acuerdo con la información del SICE (2019). 


\section{Gráfico 2. Evolución de la IED en Colombia 1970-2018}

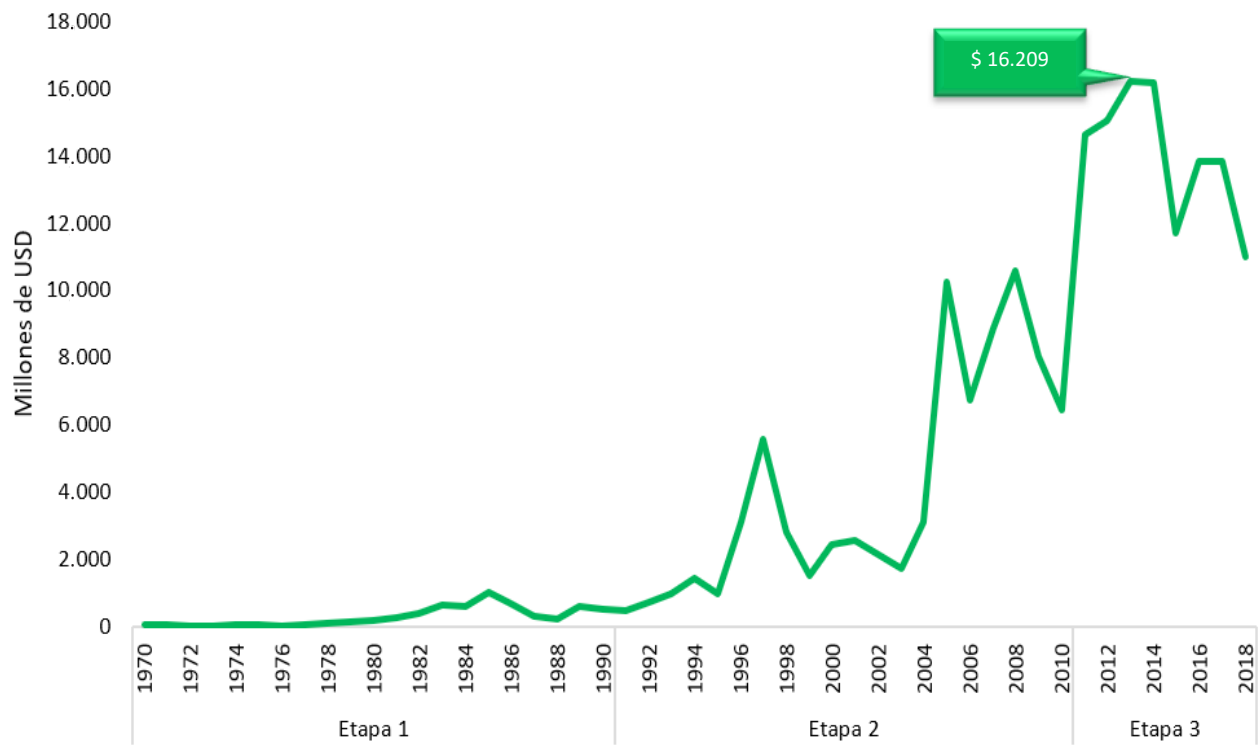

Fuente: elaboración propia con datos de la Unctad.

Uno de los principales cambios que ha provocado el nuevo régimen de IED en Colombia, ha sido el aumento de la inversión en otros sectores no tradicionales, como se puede observar en el gráfico 3. Si bien, inicialmente la IED se concentraba en la explotación de recursos naturales e industrias manufactureras existentes, este panorama parece haber cambiado, volcando la mirada hacia otros sectores distintos al minero energético, que llegó a alcanzar una participación del 76,5 \% en el año 2010. Sectores como el de transportes, almacenamiento y comunicaciones, han registrado aumentos sostenidos durante el período 2003-2018, alcanzando una participación del 24,5 \% en el año 2017. El sector de manufacturas, por su parte, se ha mantenido constante, con algunos altibajos, no obstante, su participación promedio anual es del $16,7 \%$.

El aumento de la IED para sectores diferentes al minero energético se debe principalmente a las decisiones de reinversión de las utilidades del capital extranjero en Colombia, que son estimuladas bajo un escenario de bajas tasas de interés en los países desarrollados, y la reducción del riesgo en los países emergentes (Garavito et al., 2014).

Al analizar la posición de Colombia frente a las principales economías de Latinoamérica, se puede observar cómo el país, al igual que Brasil, Chile, Argentina, México y Perú, han experimentado un crecimiento sostenido desde la década de 
1990, periodo en el cual inició la apertura económica en la gran mayoría de los países latinos (ver gráfico 4). En orden de importancia, el país que recibe más flujos de inversión directa es Brasil, con un promedio anual de USD 19.998 millones, seguido por México con USD 13.055 millones, Chile con USD 5.601 millones, Argentina con USD 4.447 y Colombia con USD 4. 055 millones. En este sentido, Colombia participa aproximadamente con el $7 \%$ de la IED en la región, mientras que Brasil y México con el $35 \%$ y $23 \%$, respectivamente.

\section{Gráfico 3. Evolución de la IED en Colombia 2003-2018}

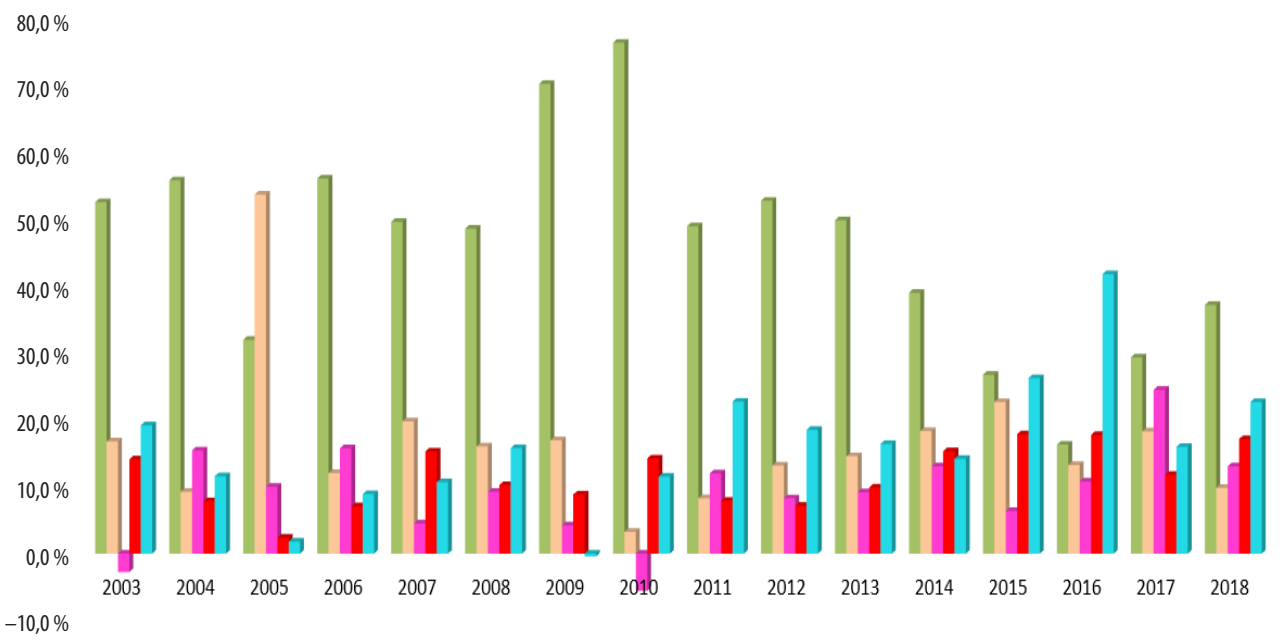

Minero energético Manufactureras $\square$ Transportes, Almacenamiento y Comunicaciones $\square$ Servicios Financieros y Empresariales $\square$ Otros

Fuente: elaboración propia con datos del Banco de la República.

El panorama de la IED en el mundo evidencia un aumento con algunos puntos de inflexión en los años 2003, 2008 y 2013, como se puede ver en el gráfico 5. Se puede notar que en el caso de América Latina y el Caribe, el impacto en estos años no fue tan significativo en comparación con las otras regiones del mundo. Las economías desarrolladas participan en la IED total con un $60 \%$, seguidas de las economías en desarrollo y Europa con un 37 \%, Asia con 28 \% y América Latina y el Caribe con tan solo el 9 \% de la IED total. Un importante aspecto a resaltar es que, a partir del año 2016, la IED en el mundo, las economías desarrolladas y Europa revelan un

\footnotetext{
${ }^{10} \mathrm{El}$ sector minero energético se compone del sector petróleo y minas y canteras (incluye carbón). En "otros", se incluyen los sectores de baja participación: electricidad, gas y agua, construcción, comercio, restaurantes y hoteles, y servicios comunales.
} 
proceso de reducción en los flujos entrantes de capital, mientras que este efecto no se refleja en tres de los grupos de países analizados: América Latina y el Caribe, Asia y las economías en desarrollo, que muestran un comportamiento estable y con tendencia creciente, lo que puede traducirse en una oportunidad para la región y por supuesto para Colombia.

Pese a las turbulencias del mercado mundial durante los años 2017 y 2018 debido a las disputas comerciales, tecnológicas y de política de seguridad entre Estados Unidos, China y la Unión Europea -que no prevén una solución rápida de los conflictos en el corto plazo- estas disputas, según la Cepal (2019), pueden traducirse en incrementos de la IED en Latinoamérica dirigida a sectores que se ven afectados en baja magnitud por las políticas implementadas por los Estados Unidos, China y la Unión Europea.

Gráfico 4. Evolución de la IED en las principales economías de América Latina, 2003-2018 (millones de dólares americanos corrientes)

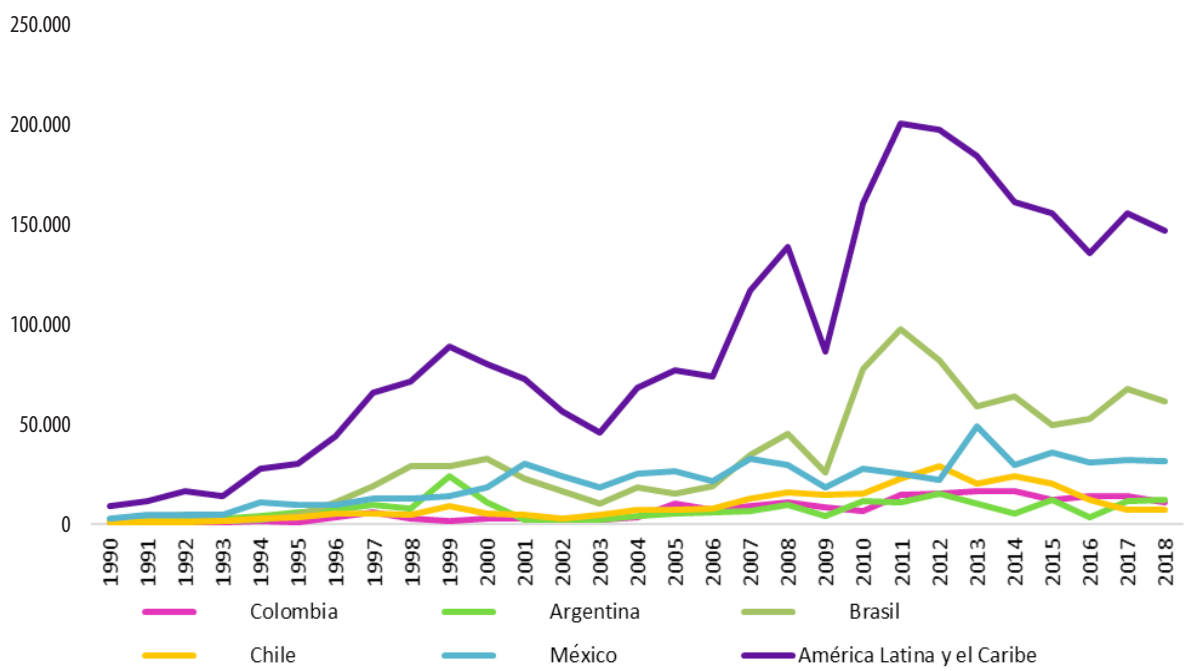

Fuente: elaboración propia con datos de la Unctad. 
Gráfico 5. Evolución de la IED en el mundo 1990-2018 (millones de dólares americanos corrientes)

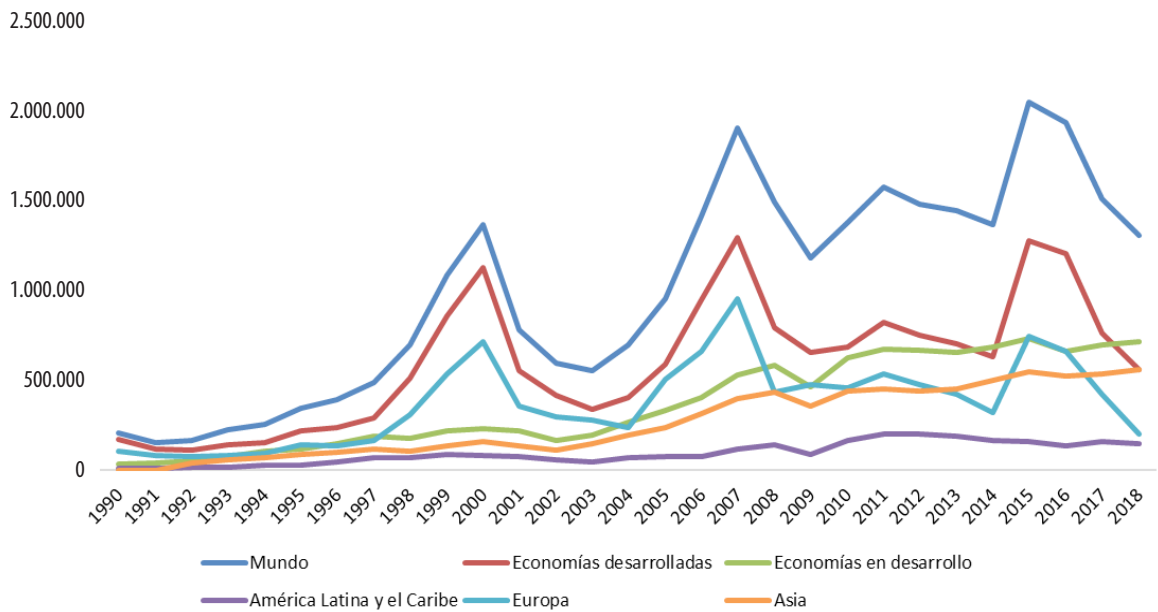

Fuente: elaboración propia con datos de la Unctad.

\section{METODOLOGÍA}

En esta sección se presenta la metodología empleada para analizar la relación entre la IED en Colombia y el riesgo soberano.

Inicialmente se presentará un análisis preliminar de las variables usadas en el estudio, así como el análisis de estacionariedad, análisis gráfico y, finalmente, se expondrán las estimaciones realizadas mediante mínimos cuadrados ordinarios y el método de momentos generalizados.

\subsection{Descripción de los datos}

Los datos usados en el análisis corresponden a la IED en Colombia durante el período 2003-2018, el EMBI (Emerging Market Bond Index) como proxy del riesgo país (riesgo soberano), y un conjunto de variables de control: la tasa de apertura, el índice de confianza comercial (ICCO) y una dummy para capturar el impacto del aumento de la IED en el año 2005. La selección del período de estudios se debe a que durante estos años se han experimentado los mayores flujos de IED en el país.

Todas las series se encuentran en periodicidad trimestral desde el año 2003 hasta 2018. A continuación, se hace un breve análisis descriptivo de las variables y se explica su relación con la IED. Las estadísticas descriptivas, así como la fuente y descripción de los datos se muestran muestran en los anexos 3 y 2, respectivamente. 
Inversión extranjera directa (IED): se hace uso de esta serie como variable dependiente en el análisis empírico. La IED mide los flujos de inversión en Colombia procedente de una persona natural o jurídica extranjera.

Riesgo soberano (riesgos): conocido también como prima de riesgo, es un dato crucial por parte de los inversionistas para evaluar en conjunto la economía. Para el propósito de este trabajo se utilizará el Embig Colombia (Emerging Market Bond Index Global) considerado como el principal indicador de riesgo soberano. Este indicador es calculado por JP Morgan Chase y es la diferencia de la tasa de interés que pagan los bonos denominados en dólares, emitidos por países subdesarrollados, y los bonos del tesoro de Estados Unidos. Como se puede observar en el gráfico 6, se espera una relación negativa entre la IED y este indicador.

Tasa de apertura económica (apertura): el nivel de apertura económica es un indicador del nivel de proteccionismo de un país, si su nivel es bajo, indica alto proteccionismo y poca libertad económica, lo que puede tener efectos en la entrada de flujos de inversión. Si bien en la literatura empírica se establece una relación positiva entre el nivel de apertura económica y los flujos de inversión, para Busse y Hefeker (2005), la dirección de esta relación depende de la orientación de la inversión. La IED puede ser de tipo horizontal y vertical: horizontal si está orientada al mercado interno y su demanda, por lo que aquí un bajo nivel de apertura y proteccionismo puede resultar atractivo para el inversionista y la relación es de carácter negativo. O puede ser vertical, asociada con la orientación a las exportaciones de la empresa inversora, donde un mayor grado de apertura y menos barreras al comercio son cruciales para atraer la IED, en este caso la relación es positiva. Como se puede observar en el gráfico 7, se espera una relación directa entre la IED y la tasa de apertura económica.

Índice de confianza comercial (ICCO): indicador de confianza de los empresarios del país. Este indicador es calculado por Fedesarrollo y busca medir la percepción de los empresarios sobre ciertos aspectos de la actividad económica. En la construcción del indicador intervienen los balances de la situación económica actual de la empresa o negocio, nivel de existencias y las expectativas sobre la situación económica para el próximo semestre. La información para el cálculo de este indicador es extraída de la Encuesta de Opinión Empresarial y cuenta con datos mensuales desde junio de 1980. Se espera que, al ser un indicador de la confianza comercial del país, tenga un impacto positivo en los flujos de IED, tal como se muestra en el gráfico 8.

Dummy2005-4: se incluye un variable binaria para evaluar el efecto de los altos flujos de inversión recibidos en el cuarto trimestre de 2005. 
Gráfico 6. Análisis de correlación IED-Embig

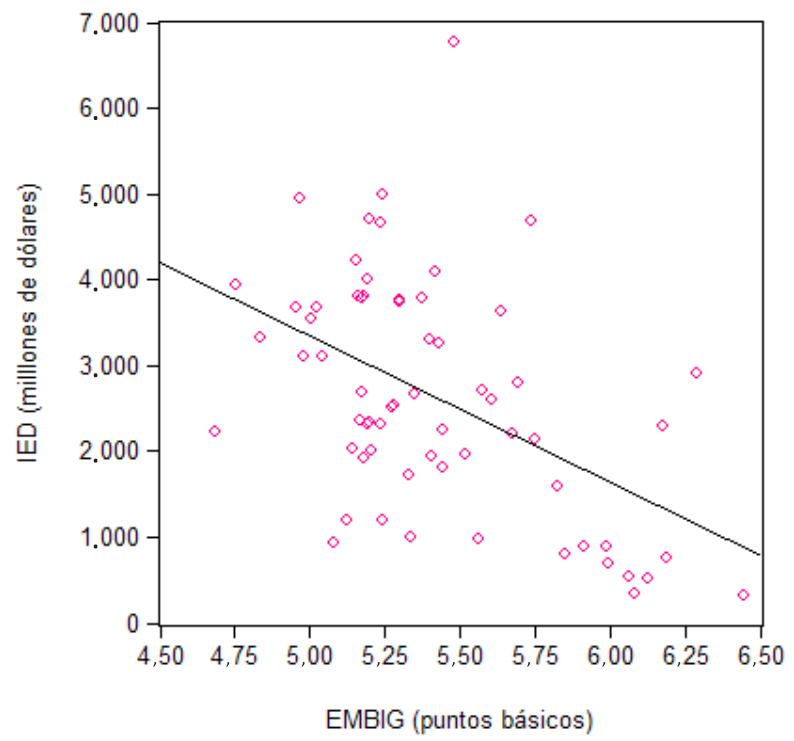

Fuente: elaboración propia en E-views 7.

Gráfico 7. Análisis de correlación IED-apertura comercial

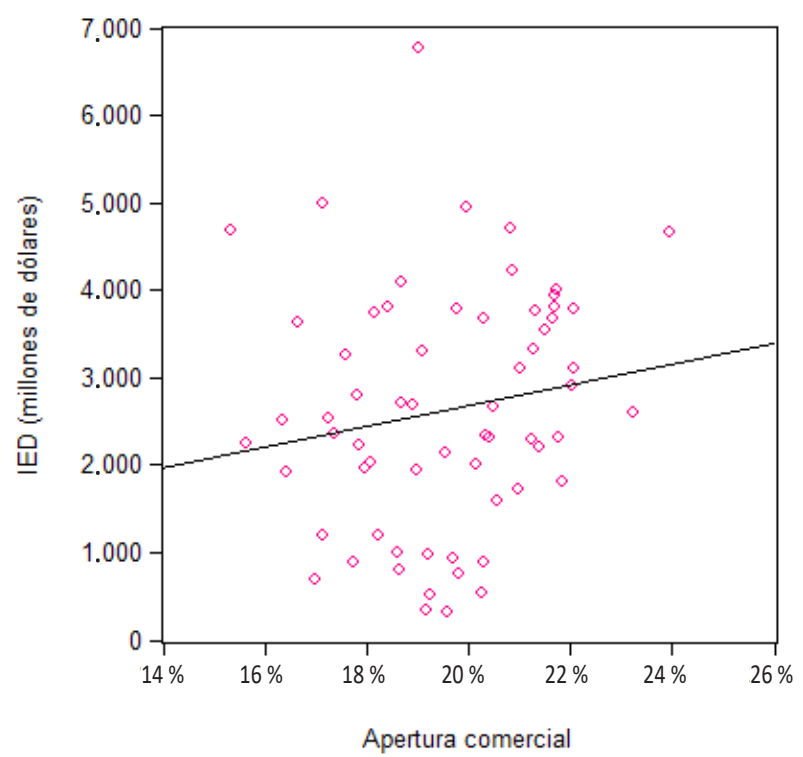

Fuente: elaboración propia en E-views 7. 


\section{Gráfico 8. Análisis de correlación IED-ICCO}

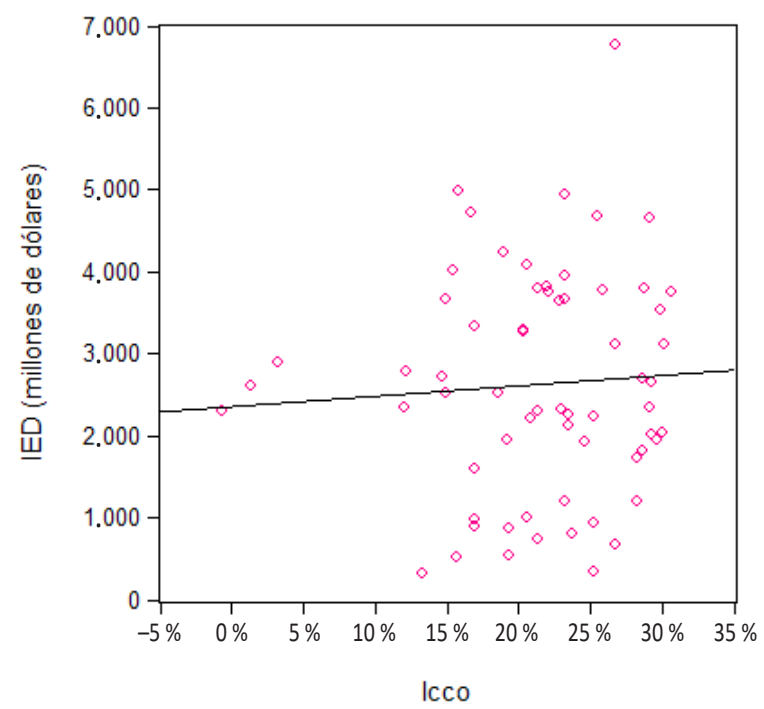

Fuente: elaboración propia en E-views 7.

\subsubsection{Análisis gráfico y estacionariedad de las series}

En esta sección se presenta el comportamiento cada una de las series incluidas en el análisis. Como se puede apreciar en el gráfico 9, la IED en Colombia, durante el período de análisis, presenta una tendencia creciente hasta el año 2015 cuando se observa una leve reducción. También se puede ver cómo en el cuarto trimestre del año 2005 se registra un aumento significativo de los flujos de inversión directa, al alcanzar un valor por USD 6.776 millones. Este aumento se puede explicar por las grandes inversiones que tuvieron lugar, de las cuales se deben mencionar la venta de Bavaria a la multinacional angloafricana SABMiller, un negocio cercano a los USD 8.000 millones, catalogado como el negocio privado más grande de la historia de Colombia; y la venta de Coltabaco a Phillips Morris por valor de USD 300 millones, entre otras inversiones de menor cuantía"1.

En cuanto a la principal variable explicativa, el Embig, se observa en el gráfico 10 cómo ha experimentado desde inicios del periodo de análisis, una reducción bastante sustancial, al pasar de 630 puntos básicos en el primer trimestre de 2003 a 211 puntos básicos en el cuarto trimestre de 2018. Es de resaltar el aumento de este indicador en el cuarto trimestre de 2008 con 538 puntos básicos, resultado de la crisis financiera que reflejó en su momento fuertes volatilidades y turbulencias

"Ver Portafolio (2005). 
en el mercado internacional. El valor promedio para el indicador en el período es de 245,64, con un mínimo de 108 puntos en el año 2007.

Gráfico 9. Inversión Extranjera Directa, 2003-2018

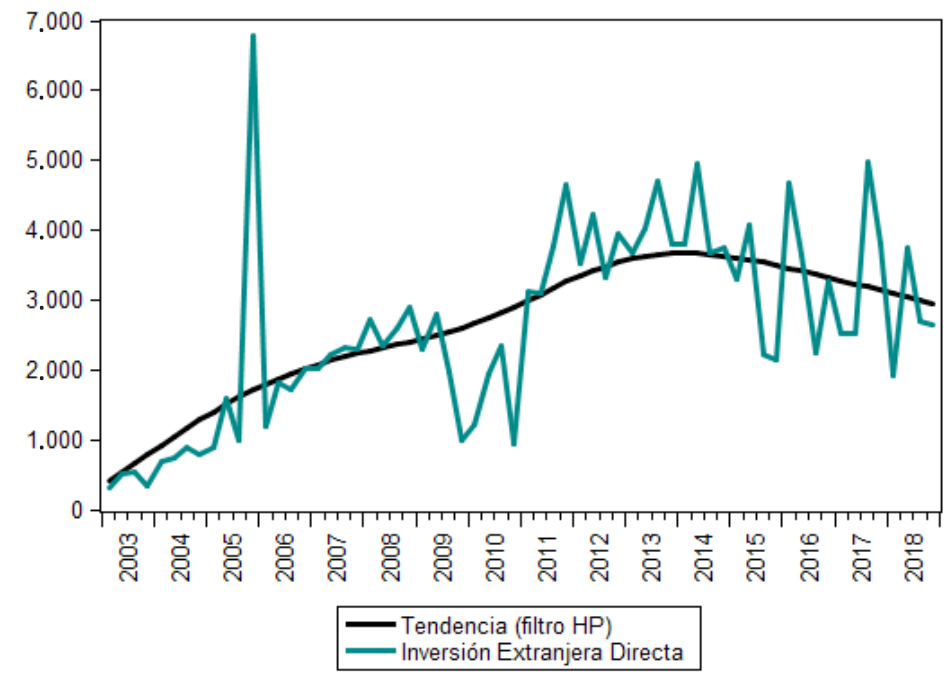

Fuente: elaboración propia en E-views 7.

Gráfico 10. Embig, 2003-2018

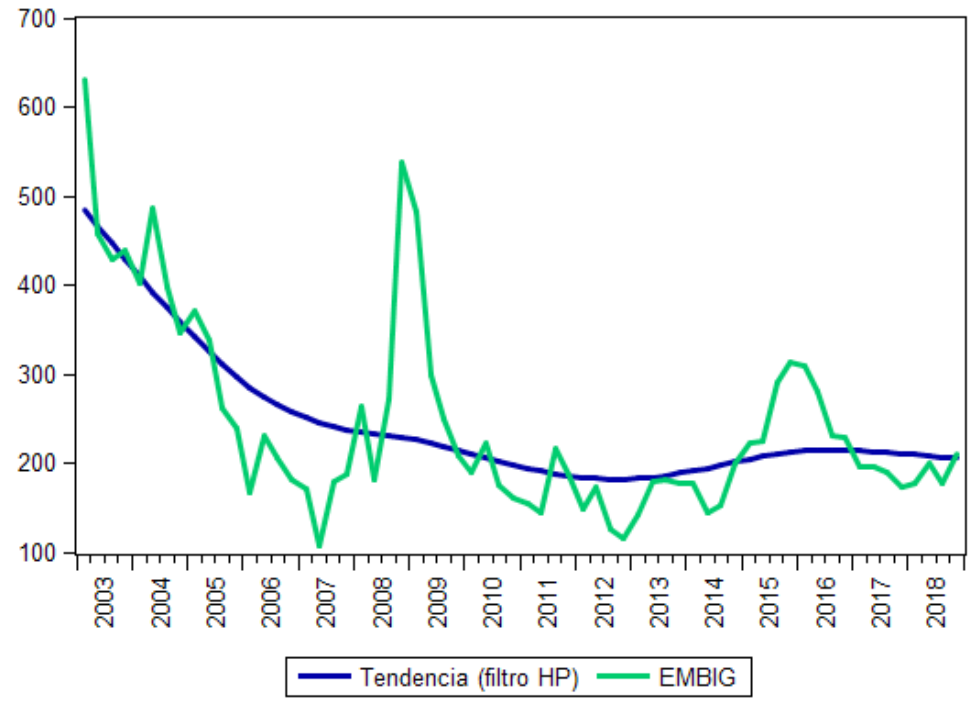

Fuente: elaboración propia en E-views 7. 
El indicador de apertura económica refleja el comportamiento del comercio total (importaciones más exportaciones) sobre el PIB. En el gráfico 11 se observa que este indicador ha mantenido una posición estable a lo largo del período de análisis, con un promedio de $19,5 \%$, fuertes caídas a finales del año 2009 y principios del 2010 , y con una tendencia decreciente desde al año 2012, aunque parece recuperarse en el cuarto trimestre del año 2018.

Gráfico 11. Tasa de apertura económica, 2003-2018

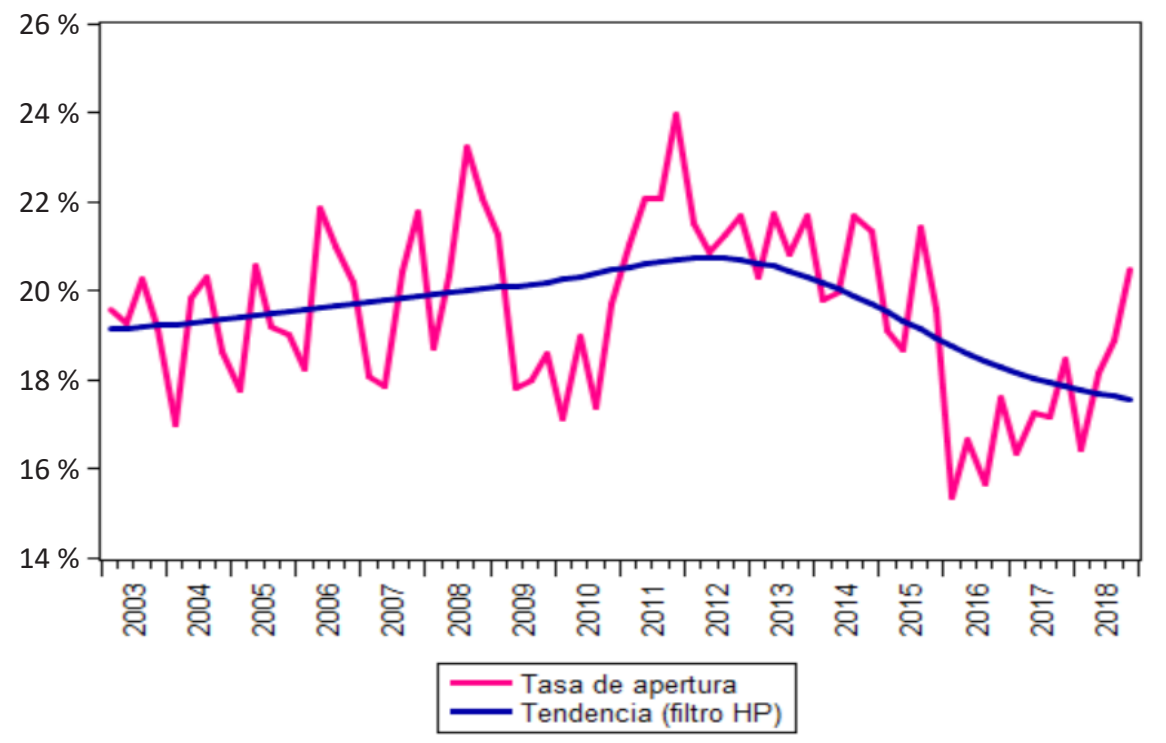

Fuente: elaboración propia en E-views 7.

El ICCO por su parte, también ha seguido un comportamiento estacionario con una reducción sustancial en el 2008 y principios del año 2009, esta reducción puede atribuirse a los efectos de la crisis financiera sobre la confianza de los agentes privados del país.

Para determinar la especificación del modelo, es fundamental analizar la estacionariedad de las series a incluir. En el anexo 1 se muestran los test de estacionariedad aplicados a las series, ADF, Phillips Perrón y KPSS. En el caso del Embig, se optó por tomar esta variable en logaritmo para facilitar la interpretación de su efecto sobre a IED. Se puede ver en el anexo 1, como todas las variables en niveles son estacionarias al nivel de $5 \%$, e integradas de orden I (0), lo que permite incluirlas en el modelo en su forma original. 
Gráfico 12. Índice de Confianza Comercial, 2003-2018

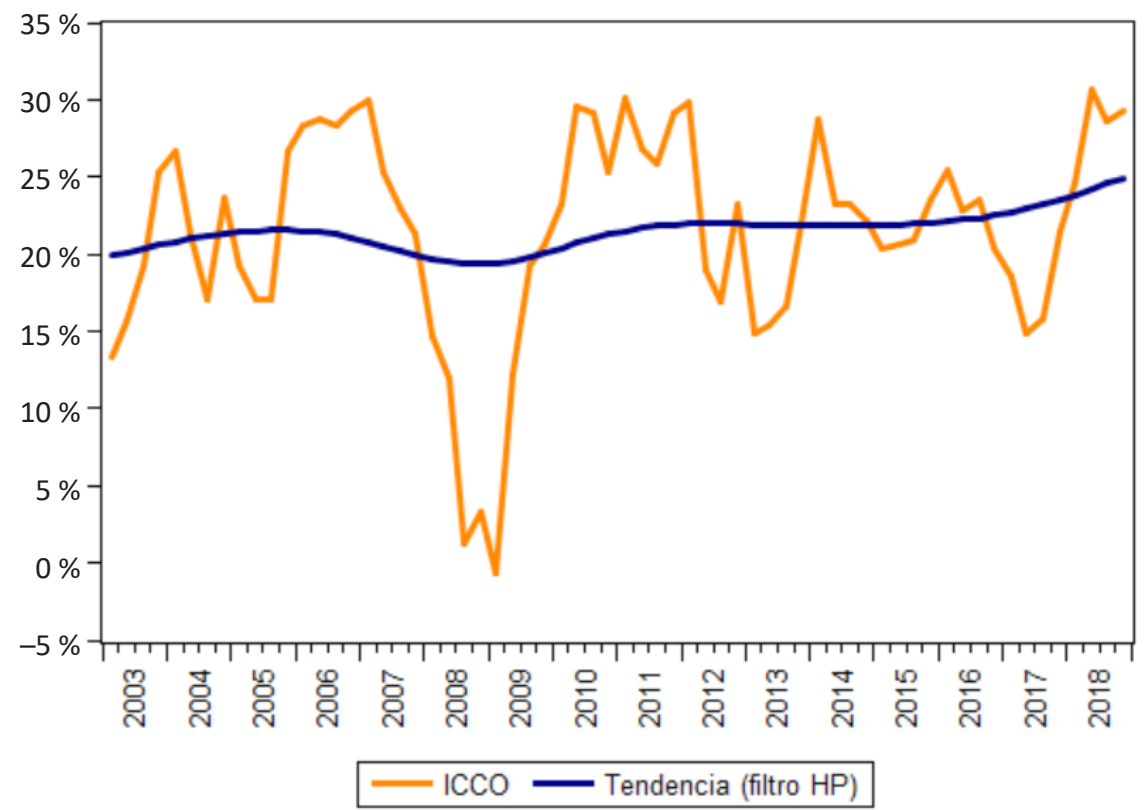

Fuente: elaboración propia en E-views 7.

\section{ESTIMACIÓN Y RESULTADOS}

El análisis de estacionariedad permite incluir las variables en niveles, por lo que es posible especificar el siguiente modelo:

$$
\text { ied }_{t}=\beta_{0}+\beta_{1} \text { embig }_{t}+\beta_{2} \text { apertura }_{t-2}+\beta_{3} \text { icco }_{t-7}+\beta_{4} \gamma+e_{t}
$$

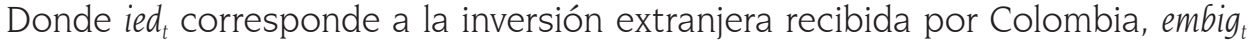
es el logaritmo natural de Embig, apertura es la tasa de apertura económica, icco corresponde al índice de confianza comercial y $\gamma$ es una dummy para capturar el efecto del aumento de la IED en el período 2005-4. Debido a que las variables macroeconómicas no responden inmediatamente a los cambios en otras variables, fue necesario determinar previamente el rezago óptimo de cada serie.

En la tabla 1 se muestran los resultados de la estimación realizada mediante mínimos cuadrados ordinarios con matrix HAC (Newey-West), para corregir por autocorrelación y heterocedasticidad. 
Tabla 1. Estimaciones MCO (HAC)

\begin{tabular}{lllll}
\hline \multicolumn{5}{c}{$\begin{array}{c}\text { Variable dependiente: IED } \\
\text { Periodo: 2003-2018 }\end{array}$} \\
\hline Regresoras & Modelo 1 & Modelo 2 & Modelo 3 & Modelo 4 \\
\hline C & $1.1865,19^{* * *}$ & $6.753,12^{* *}$ & $4.013,80$ & $4.729,91^{*}$ \\
\hline embig & {$[4,191]$} & {$[2,528]$} & {$[1,492]$} & {$[1,846]$} \\
\hline & $-1.703,58^{* * *}$ & $-1.526,03^{* * *}$ & $-1.020,45^{* *}$ & $-1.102,47^{* *}$ \\
\hline apertura(-2) & {$[-3,264]$} & {$[-2,86]$} & {$[-2,307]$} & {$[-2,503]$} \\
\hline & & $213,66^{* *}$ & $153,32^{*}$ & $142,99^{*}$ \\
\hline icco(-7) & & {$[2,579]$} & {$[1.897]$} & {$[1,781]$} \\
\hline & & & $61,54^{* * *}$ & $54,91^{* * *}$ \\
\hline$\gamma$ & & & {$[3,666]$} & {$[3,14]$} \\
\hline R & & & & $3679,69^{* * *}$ \\
\hline F-statistic & 19,45 & 11,23 & 6,64 & 9,76 \\
\hline P(F-stat) & 0,000 & 0,000 & 0,000 & 0,000 \\
\hline
\end{tabular}

Nota: Nivel de significancia: $\left({ }^{* * *}\right)$ denota significancia a $0,01,\left({ }^{* *}\right)$ denota significancia a $0,05,\left({ }^{*}\right)$ denota significancia a 0,1. Estadístico-t entre corchetes. P(F-stat) reporta el valor $\mathrm{p}$ del test $\mathrm{F}$ de significancia de la regresión.

Fuente: elaboración propia.

Una vez estimada la ecuación 1, se observa que el modelo con mejor ajuste y significancia es el modelo 4. No obstante, las pruebas de diagnóstico para detectar autocorrelación y heterocedasticidad presentadas en la tabla 2, muestran que se debe rechazar la hipótesis nula de no autocorrelación, con un valor p de 0,005, por lo que no es posible hacer inferencia estadística sobre esta estimación.

Para corregir el problema anterior, se procede a estimar el modelo 4 mediante el método de momentos generalizado (MMG). Si bien el los estimadores de MCO son útiles, ante presencia de autocorrelación o heterocedasticidad, dejan de ser confiables y consistentes, mientras que el MMG permite realizar inferencia al no hacer supuestos sobre los residuos. En la tabla 3 se presentan las estimaciones del modelo 4 mediante GMM, para efectos comparativos también se muestran las estimaciones por MCO. 
Tabla 2. Test de diagnóstico para los residuos MCO

\begin{tabular}{lcll}
\hline \multicolumn{4}{c}{ Breusch-Godfrey Serial Correlation LM Test: } \\
\hline F-statistic & 8,466268 & Prob. F(1,51) & 0,0053 \\
\hline Obs*R-squared & 8,115143 & Prob. Chi-Square(1) & 0,0044 \\
\hline \multicolumn{4}{c}{ Heteroskedasticity Test: } \\
\hline \multicolumn{4}{c}{ Breusch-Pagan-Godfrey } \\
\hline F-statistic & 0,220491 & Prob. F(4,52) & 0,9258 \\
\hline Obs*R-squared & 0,950645 & Prob. Chi-Square(4) & 0,9172 \\
\hline Scaled explained SS & 0,626294 & Prob. Chi-Square(4) & 0,9601 \\
\hline
\end{tabular}

Fuente: cálculos en E-views 7.

Tabla 3. Estimaciones MCO (HAC) y MMG

\begin{tabular}{|c|c|c|}
\hline \multicolumn{3}{|c|}{$\begin{array}{l}\text { Variable dependiente: IED } \\
\text { Periodo: 2003-2018 }\end{array}$} \\
\hline Regresoras & Modelo 4 MCO (HAC) & Modelo 4 MMG \\
\hline \multirow[t]{2}{*}{$\mathrm{C}$} & $4.729,91^{*}$ & $6.453,17^{* * *}$ \\
\hline & {$[1,846]$} & {$[3,526]$} \\
\hline \multirow[t]{2}{*}{ embig } & $-1.102,47^{* *}$ & $-1.365,11^{* * *}$ \\
\hline & {$[-2,503]$} & {$[-4,222]$} \\
\hline \multirow[t]{2}{*}{ apertura $(-2)$} & $142,99 *$ & $115,34^{* *}$ \\
\hline & {$[1,781]$} & {$[1,980]$} \\
\hline \multirow[t]{2}{*}{$i c c o(-7)$} & $54,91^{* * *}$ & $67,96^{* * *}$ \\
\hline & {$[3,14]$} & {$[3,835]$} \\
\hline \multirow[t]{2}{*}{$\gamma$} & $3.679,69^{* * *}$ & $3.490,49^{* *}$ \\
\hline & {$[19,08]$} & {$[2,477]$} \\
\hline $\mathrm{R}^{2}$ ajust, & 0,38 & 0,32 \\
\hline F-statistic & 9,76 & \\
\hline $\mathrm{P}$ (F-stat) & 0,000 & \\
\hline J-statistic & & 7,57 \\
\hline P(J-statistic) & & 0,87 \\
\hline N. ${ }^{\circ}$ instrumentos & & 18 \\
\hline
\end{tabular}

Nota: Nivel de significancia: $\left({ }^{* * *}\right)$ denota significancia a $0,01,\left({ }^{* *}\right)$ denota significancia a $0,05,\left({ }^{*}\right)$ denota significancia a 0,1. Estadístico-t entre corchetes. P(F-stat) reporta el valor $\mathrm{p}$ del test $\mathrm{F}$ de significancia de la regresión. Instrumentos: embig (-1) apertura( -1 to -3$)$ icco (-1 to -6) ieddolares ( -1 to -3$)$ dummy $(-6$ to -9$)$.

Fuente: elaboración propia. 
De los resultados obtenidos y presentados en la tabla 3 se puede inferir lo siguiente: el parámetro asociado al Embig es estadísticamente significativo al 1 \%, y en comparación con las demás variables explicativas, salvo la variable dummy, refleja un impacto sustancial en los niveles de inversión extranjera directa. Así, ante un cambio de $1 \%$ en el Embig, la IED disminuye en USD 1.365,11 millones, confirmando, además, el signo esperado de la relación entre las dos variables. Lo anterior sugiere que se debe tener prudencia con los factores que internamente pueden reflejar algún tipo de impacto en esta medida de riesgo, tal como aumentos en la deuda externa, aumentos en el déficit público o cualquier otra variable asociada con las finanzas públicas del país, pues esto se traduce en reducciones en los niveles de IED, debido al mensaje negativo que se emite a los inversionistas extranjeros sobre el estado de la economía local.

La magnitud del efecto de la tasa de apertura económica es menor con relación al Embig y es significativa al $5 \%$. El valor del coeficiente estimado indica que ante un incremento de la tasa de apertura en 1 \%, la IED aumenta USD 115,34 millones. Tal como la evidencia internacional sugiere, aumentos en el comercio internacional de un país, indican menos barreras comerciales y, por tanto, aumenta la posibilidad de establecerse en un determinado país.

En cuanto al ICCO, presenta una alta significancia (1 \%) y señala que al aumentar un $1 \%$, la IED se incrementa en USD 67,96 millones. Esto da cuenta de la importancia que tiene la percepción de los agentes privados del país, si esta aumenta, es posible obtener mayores flujos de IED, dado que se transmiten señales de estabilidad comercial. En cuanto al ajuste del modelo, el $\mathrm{R}^{2}$ ajustado es de 0,32, lo cual indica que las variables incluidas en el análisis explican en un 32 \% la variación en la IED. Se resalta que el Embig explica el 22 \% de la variación total en la IED colombiana (ver modelo en la tabla 1), ratificando su poder explicativo y su importancia al ser una variable que afecta las decisiones de inversión.

\section{ROBUSTEZ}

Para validar el efecto de riesgo soberano en los flujos de inversión entrantes en Colombia, se hace uso de un modelo VAR (vector autorregresivo). Para este ejercicio se aplica la función de impulso respuesta generalizada con las variables de riesgo soberano e IED, y mediante el criterio Hannan Quinn se obtiene el orden del rezago, en este caso 1 (ver tabla 4). Se establece también un máximo de 10 periodos en el análisis. 
Tabla 4. Selección orden del rezago VAR

\begin{tabular}{cccc}
\hline Lag & AIC & SC & HO \\
\hline 0 & 17,44658 & 17,66164 & 17,53016 \\
\hline 1 & $16,60746 *$ & $16,96589^{*}$ & $16,74676^{*}$ \\
\hline 2 & 16,66291 & 17,16471 & 16,85793 \\
\hline 3 & 16,73860 & 17,38377 & 16,98933 \\
\hline 4 & 16,86041 & 17,64896 & 17,16687 \\
\hline 5 & 16,96719 & 17,89911 & 17,32937 \\
\hline 6 & 16,97653 & 18,05182 & 17,39442 \\
\hline
\end{tabular}

Fuente: elaboración propia en E-views 7.

Como se puede ver, el gráfico 13 muestra los resultados del VAR, los cuales sugieren que un choque positivo en el Embig provoca una reducción en la IED. Esto significa que la IED es bastante sensible a los cambios en el riesgo soberano, si este aumenta (debido a eventos internos del país, conflictos políticos, mal manejo de las finanzas públicas, entre otros, que se pueden percibir de manera negativa por los inversionistas y agentes externos como las calificadoras de riesgo), esto provoca una reducción significativa en la IED. Cabe resaltar que la significancia se verifica en los periodos 3, 4, 5, 6 y 7 .

Gráfico 13. Respuesta acumulada de la IED ante un choque en el Embig

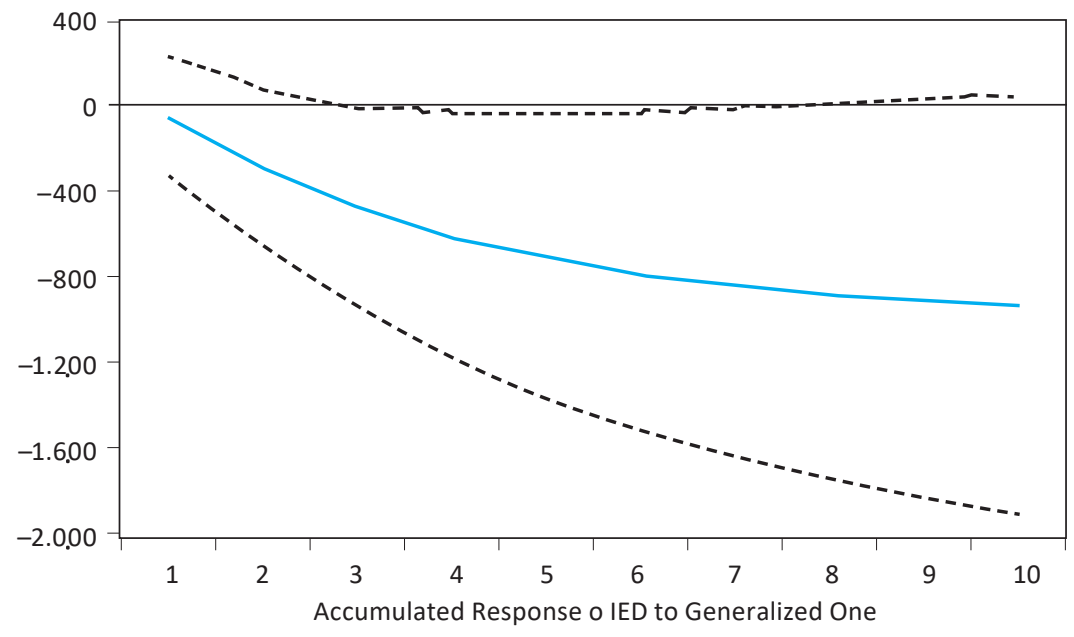

S.D. EMBIG Innovation

Fuente: elaboración propia en E-views 7. 


\section{CONCLUSIONES}

Este estudio exploró el rol del riesgo soberano como determinante principal de los flujos de inversión en Colombia en el periodo 2003-2018. Trabajos recientes como los de Rafat y Farahani (2019), indican que el nivel de riesgo afecta de manera negativa los flujos de inversión que recibe un país. No obstante, no existe evidencia empírica para Colombia, pues los trabajos en torno al tema son de tipo microeconómico o descriptivo. Bajo los hallazgos obtenidos en este análisis se concluye que el riesgo soberano tiene un impacto sustancial en la atracción de la IED, pues constituye un elemento vital en la toma de decisiones de inversionistas y multinacionales sobre dónde localizar sus recursos y actividades.

El análisis de regresión y el modelo VAR sugieren un alto impacto del riesgo soberano sobre la IED en Colombia. Si bien el ajuste del modelo es bueno, futuros trabajos podrían enfocarse en investigar otras variables que podrían afectar la IED, esto es, capacidades tecnológicas, variables asociadas con el tamaño del mercado y el nivel educativo, costos laborales, entre otras variables que, dado el enfoque de este trabajo (series de tiempo), no fue posible usar debido a la periodicidad de los datos. También es posible evaluar el riesgo con otra variable como el nivel de deuda externa o déficit público.

Finalmente, es conveniente que los agentes gubernamentales tengan en cuenta el hecho de que la inestabilidad política, el manejo proco prudente de las finanzas públicas, entre otros elementos que pueden afectar el Embig y otras calificaciones de riesgo internacional, juegan un papel importante en la determinación de la IED y, en consecuencia, en el desempeño económico a largo plazo del país.

\section{BIBLIOGRAFÍA}

Amal, Mohamed; Tomio, Bruno y Raboch, Henrique (2010). Determinants of Foreign Direct Investment in Latin America. En: GCG. Revista de Globalización, Competitividad y Gobernabilidad, vol. 4, n. ${ }^{\circ}$, p. 116- $\overline{133}$.

Bakar, Nor'Aznin; Mat, Siti Hadijah Che y Harun, Mukaramah (2012). The Impact of Infrastructure on Foreign Direct Investment: The Case of Malasia. En: Procedia - Social and Behavioral Sciences, vol. 65, p. 205-211. Doi: 10.1016/j.sbspro.2012.11.112

Botero, Martín (2011). Evolution of foreign direct investment in Colombia and why is Colombia becoming an important destination of foreign direct investment. Bogotá: Colegio de Estudios Superiores de Administración, 84 p.

Busse, Matthias y Hefeker, Carsten (2005). Political risk, institutions and foreign direct investment. Hamburgo: Hamburg Institute of International Economics, 28 p.

Cepal -Comisión Económica para América Latina. (2019). la inversión extranjera directa en América Latina y el Caribe. Santiago de Chile: Cepal, 190p. 
Congreso de la República. (1991). Ley 9 de enero 17 por medio de la cual se dictan normas generales a las que deberá sujetarse el Gobierno Nacional para regular los cambios internacionales y se adoptan medidas complementarias. Diario Oficial 39.634 de enero 17 de 1991.

Correa, Eduarda; Dias, Jorge y Triches, Divanildo (2017). The determinants of foreign direct investment in Brazil: empirical analysis for 2001-2013. En: Cepal Review, n. ${ }^{\circ} 121$, p. 171-184.

Echavarría, Juan y Zodrow, George (2003). Foreign Direct Investment and Tax Structure in Colombia. Washington: Banco Interamericano de Desarrollo, 36 p.

Fedesarrollo -Fundación para la Educación Superior y el Desarrollo (2007). Impacto de la inversión extranjera en Colombia: situación actual y perspectivas. Recuperado de https://www. repository.fedesarrollo.org.co/bitstream/handle/11445/979/Repor_Diciembre _ 2007 _ Fedesarrollo.pdf?sequence $=1$ EisAllowed $=\mathrm{y}$

Garavito, Aarón; Gaitán, Celina; Sandoval, Diego y Martínez, Adrián (2014). Foreign Direct Investment in Colombia: developments and prospects. Recuperado de https://www.banrep.gov. co/sites/default/files/publicaciones/archivos/isi_boxl_mar_ingles_2014.pdf

Garavito, Aarón; Iregui, Ana María y Ramírez, María Teresa (2012). Determinantes de la inversión extranjera directa en Colombia: Un estudio a nivel de firma. En: Borradores de Economía, n. $714,52 \mathrm{p}$.

Gil, Edgar; López, Silvio y Espinosa, Dorian (2013). Factores determinantes de la inversión extranjera directa en América del Sur. En: Perfil de Coyuntura Económica, n. ㅇ 22, p. 55-85.

Hayakawa, Kazunobu; Kimura, Fukunari y Lee, Hyun-Hoon (2013). How Does Country Risk Matter for Foreign Direct Investment? En: Developing Economies, vol. 51 n. ${ }^{\circ}$ 1, p. 60-78.

Hunady, Jan y Orviska, Marta (2014). Determinants of Foreign Direct Investment in EU Countries Do Corporate Taxes Really Matter? En: Procedia Economics and Finance, vol. 12, p. 243-250.

Ismail, Ibrahim (2017). An Empirical Study on Country Risk as A Predictor of Market Entry Decisions: Impact of Political, Economic and Financial Risks on FDI Inflows of Horn of Africa and Middle East North Africa Region (MENA). En: Journal of International Business Research and Marketing, vol. 2, n. ${ }^{\circ}$ 5, p. 24-32.

Kalin, Ylva (2009). FDI in Colombia: Policy and Economic Effects. Recuperado de http://lup.lub. lu.se/luur/download?func $=$ downloadFileErecordOId $=1504612$ EfileOId $=1647124$

Mattos, Leonardo; Cassuce, Francisco y Campos, Antonio (2007). Determinantes dos investimentos diretos estrangeiros no brasil, 1980-2004. En: Revista de Economia Contemporânea, vol. 11, n. ${ }^{\circ} 1$, p. 39-60.

O'Meara, Graeme (2015). Examining the Determinants of Foreign Direct Investment. En: Undergraduate Economic Review, vol. 11, n. ${ }^{\circ} 1,19 \mathrm{p}$.

Rafat, Monireh y Farahani, Maryam (2019). The Country Risks and Foreign Direct Investment (FDI). En: Iranian Economic Review, vol. 23, n. 1, p. 235-260.

SICE -Sistema de Información sobre Comercio Exterior- (2019). Información sobre Colombia. Recuperado de http://www.sice.oas.org/ctyindex/COL/COLBITS_s.asp 
Sissani, Midoun y Belkacem, Zairi (2014). The impact of country risk components on Algeria attractiveness for foreign direct investments (1990-2012). En: Applied Econometrics and International Development, vol. 14, n. ${ }^{\circ}$ 1, p. 133-146.

Tocar, Sebastian (2018). Determinants of Foreign Direct Investment: A Review. En: Review of Economics and Business Studies, vol. 11, n. ${ }^{\circ}$ 1, p. 165-196.

Türedi, Salih (2018). The effect of corruption and country risk on FDI inflows: empirical evidence from developing countries. En: International Journal of Economics and Administrative Studies, n. ${ }^{\circ} 21$, p. 151-172. 


\section{ANEXOS}

\section{Anexo 1. Test de raíz unitaria y estacionariedad}

\begin{tabular}{|c|c|c|c|c|c|c|c|c|c|c|c|c|c|}
\hline \multirow[b]{2}{*}{ Series } & \multicolumn{4}{|c|}{ ADF } & \multicolumn{4}{|c|}{ Phillips Perron } & \multicolumn{4}{|c|}{ KPSS } & \multirow[t]{2}{*}{ Resultado } \\
\hline & Lags & Esp. & Test & $\begin{array}{l}\text { C. V } \\
\text { (5\%) }\end{array}$ & Band & Esp. & Test & $\begin{array}{l}\text { C. V } \\
\text { (5\%) }\end{array}$ & Band & Esp. & Test & $\begin{array}{l}\text { C. V } \\
\text { (5\%) }\end{array}$ & \\
\hline ied & 0 & $\mathrm{CT}$ & $-6,12$ & $-3,48$ & 4 & $\mathrm{CT}$ & $-6,34$ & $-3,48$ & 5 & $\mathrm{CT}$ & 0,144 & 0,146 & I $(0)$ \\
\hline embig & 0 & $\mathrm{C}$ & $-3,21$ & $-2,90$ & 1 & $\mathrm{C}$ & $-3,22$ & $-2,90$ & 5 & $\mathrm{CT}$ & 0,143 & 0,146 & I $(0)$ \\
\hline apertura & 0 & $\mathrm{C}$ & $-3,93$ & $-2,90$ & 1 & $\mathrm{C}$ & $-3,90$ & $-2,90$ & 5 & $\mathrm{C}$ & 0,19 & 0,46 & $\mathrm{I}(0)$ \\
\hline icco & 0 & $\mathrm{CT}$ & $-2,79$ & $-2,90$ & 3 & C & $-3,13$ & $-2,90$ & 5 & $\mathrm{C}$ & 0,07 & 0,46 & I $(0)$ \\
\hline
\end{tabular}

Nota: C.V. = valor crítico. Tendencia (T), y/o constante (C), o Ni tendencia ni Constante (N) son incluidas con base en el criterio de información de Schwarz. El test KPSS fue utilizado con banda Newey-West.

Fuente: elaboración propia.

\section{Anexo 2. Fuente y descripción de las variables}

\begin{tabular}{lll}
\hline Variable & \multicolumn{1}{c}{ Descripción } & \multicolumn{1}{c}{ Fuente } \\
\hline ied & $\begin{array}{l}\text { Inversión extranjera directa en Colombia en } \\
\text { millones de dólares }\end{array}$ & $\begin{array}{l}\text { Banco de la República (http://www. } \\
\text { banrep.gov.co/) }\end{array}$ \\
\hline riesgop & Embig (Emerging Market Bond Index Global) & $\begin{array}{l}\text { Banco Central de Reserva del Perú } \\
\text { (https://estadisticas.bcrp.gob.pe) }\end{array}$ \\
\hline icco & Índice de confianza comercial (\%) & $\begin{array}{l}\text { Fedesarrollo (https://www.fedesarrollo. } \\
\text { org.co/) }\end{array}$ \\
\hline apertura & $\begin{array}{l}\text { Nivel de apertura económica (\%), construido } \\
\text { como el total de importaciones más impor- } \\
\text { taciones entre el PIB corriente: }\end{array}$ & $\begin{array}{l}\text { Banco de la República (http://www. } \\
\text { banrep.gov.co/) }\end{array}$ \\
\hline
\end{tabular}

Fuente: elaboración propia.

\section{Anexo 3. Estadísticas descriptivas}

\begin{tabular}{lccccc}
\hline \multicolumn{1}{c}{ Variable } & Media & Mediana & Máximo & Mínimo & Desviación estándar \\
\hline ied & $2.628,469$ & $2.519,500$ & $6.776,00$ & 319 & $1.365,47$ \\
\hline embig & 245,64 & 203 & 630 & 108 & 110,78 \\
\hline icco & 21,48594 & 22,50 & $-0,700$ & 30,70 & 6,791822 \\
\hline apertura & 19,55868 & 19,64617 & 23,9426 & 15,34133 & 1,89 \\
\hline
\end{tabular}

Fuente: elaboración propia en E-views 7. 